\title{
Photoinduced 1,2-Hydro(cyanomethylation) of Alkenes with a Cyanomethylphosphonium Ylide
}

\author{
Tomoya Miura* (iD) \\ Daisuke Moriyama \\ Yuuta Funakoshi \\ Masahiro Murakami* (D) \\ Department of Synthetic Chemistry and Biological Chemistry, Kyoto \\ University, Katsura, Kyoto 615-8510, Japan \\ tmiura@sbchem.kyoto-u.ac.jp \\ murakami@sbchem.kyoto-u.ac.jp \\ Published as part of the 30 Years SYNLETT - Pearl Anniversary Issue
}

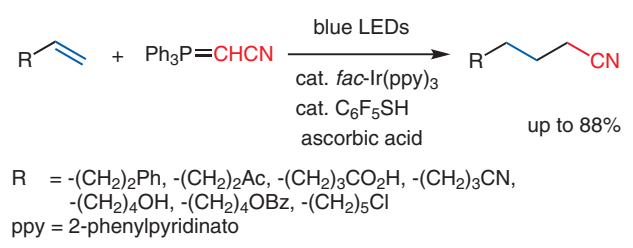

ppy $=2$-phenylpyridinato

\author{
Received: 22.12 .2018 \\ Accepted after revision:23.01.2019 \\ Published online: 13.02 .2019 \\ DOI: 10.1055/s-0037-1612230; Art ID: st-2018-b0826-I
}

License terms: (c)

Abstract An efficient method has been developed for the 1,2-hydro(cyanomethylation) of alkenes, in which a cyanomethyl radical species is generated from a cyanomethylphosphonium ylide by irradiation with visible light in the presence of an iridium complex, a thiol, and ascorbic acid. The cyanomethyl radical species then adds across the $\mathrm{C}=\mathrm{C}$ double bond of an alkene to form an elongated alkyl radical species that accepts a hydrogen atom from the thiol to produce an elongated aliphatic nitrile. The ascorbic acid acts as the reductant to complete the catalytic cycle.

Key words alkenes, nitriles, photocatalysis, radicals, phosphonium ylides, hydro(cyanomethylation)

Radical chemistry has undergone a renaissance since the introduction of photoredox catalysis, ${ }^{1}$ and a wide variety of reagents are now available as competent precursors to radical species. We recently reported that an ester-stabilized phosphonium ylide ${ }^{2}$ can act as a precursor to an (alkoxycarbonyl)methyl radical species ${ }^{3}$ when irradiated with visible light in the presence of an iridium catalyst, a thiol, and ascorbic acid. ${ }^{4}$ The radical species, substituted by an electron-withdrawing alkoxycarbonyl group, adds across the $\mathrm{C}=\mathrm{C}$ double bond of an alkene to generate an elongated alkyl radical. Subsequently, the thiol delivers a hydrogen atom to the radical, ${ }^{5}$ producing an elongated aliphatic ester. ${ }^{6}$

We also examined the use of a cyanomethylphosphonium ylide instead of an ester-stabilized phosphonium ylide. The former act as the precursor of a cyanomethyl radical species $^{7-10}$ that, due to the electron-withdrawing nature of the cyano group, is sufficiently electrophilic to attach to a $\mathrm{C}=\mathrm{C}$ double bond of an alkene, as in the case of an (alkoxycarbonyl)methyl radical., ${ }^{3,6}$ The appended alkyl radical species is not as electrophilic as the original cyanomethyl radical, and can therefore abstract a hydrogen atom from a sulfanyl group 5 to form an elongated aliphatic nitrile.

Initially, we applied the conditions optimized for the reaction of an ester-stabilized phosphonium ylide ${ }^{4}$ to the reaction of the cyanomethylphosphonium ylide 2 with 4phenylbut-1-ene (1a), and we obtained 6-phenylhexanenitrile (3a) as expected. The yield, however, was moderate ( $43 \%$ by NMR), which led us to adapt the reaction conditions slightly to fit the ylide $\mathbf{2}$. The elongated nitrile $\mathbf{3 a}$ was produced in 94\% NMR yield and $80 \%$ isolated yield when 1a ( $0.50 \mathrm{mmol})$ was treated with $2(1.0 \mathrm{mmol}, 2.0$ equiv) in $1: 1$ $\mathrm{CH}_{3} \mathrm{CN} / \mathrm{H}_{2} \mathrm{O}(0.1 \mathrm{M})$ under irradiation by blue light-emitting diodes (LEDs; $470 \mathrm{~nm}, 23 \mathrm{~W}$ ) in the presence of $f a c-\operatorname{Ir}(\mathrm{ppy})_{3}$ (1.0 mol\%; ppy = 2-phenylpyridinato), $\mathrm{C}_{6} \mathrm{~F}_{5} \mathrm{SH}$ (20 mol\%), ascorbic acid (10 equiv), and $\mathrm{KHSO}_{4}$ (3.0 equiv) at room temperature for 40 hours (Scheme 1 ). No product resulting from 1,2-addition in the opposite direction was observable within the detection limits of ${ }^{1} \mathrm{H}$ NMR (400 MHz). A largerscale experiment using $925 \mathrm{mg}(7.0 \mathrm{mmol})$ of 1a also gave a comparable yield of $3 \mathbf{a}$ ( $83 \%$ isolated yield), indicating the scalability of the present reaction.

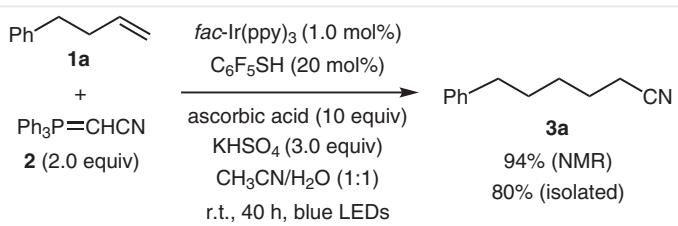

Scheme 1 1,2-Hydro(cyanomethylation) of alkene $\mathbf{1 a}$ with phosphonium ylide 2

The formation of the product 3a can be reasonably explained by assuming the radical mechanism depicted in Scheme 2, which is similar to that proposed in the case of ester-stabilized phosphonium ylides. ${ }^{4}$ First, an acid/base 
reaction of $2\left(\mathrm{p} K_{\mathrm{aH}}=6.9\right)^{11}$ with ascorbic acid $\left(\mathrm{AscH}_{2}\right.$; $\left.\mathrm{p} K_{\mathrm{a}}=4.0\right)^{12}$ generates the phosphonium ascorbate $\left[\mathrm{Ph}_{3} \mathrm{PCH}_{2} \mathrm{CN}\right]^{+}[\mathrm{AscH}]^{-}(4)$. This has an energetically low-lying $\sigma^{*}$ orbital for the C-P linkage. The Ir catalyst [fac$\left.\operatorname{Ir}(\text { ppy })_{3}\right][\operatorname{Ir}(\mathrm{III})]$ is photoexcited by visible light to form the excited species $[\operatorname{Ir}(\mathrm{III})]^{*}$. This then transfers a single electron to the $\sigma^{*}$ orbital of the phosphonium ascorbate 4 , giving rise to the cyanomethyl radical species 5, along with $\mathrm{PPh}_{3}$ and $[\operatorname{Ir}(\mathrm{IV})]^{+}[\mathrm{AscH}]^{-}$. Electrophilic addition of 5 to the $\mathrm{C}=\mathrm{C}$ double bond of alkene 1a affords the elongated secondary alkyl radical species $\mathbf{6}$, which is less electrophilic than 5. Hydrogen-atom transfer from $\mathrm{C}_{6} \mathrm{~F}_{5} \mathrm{SH}$ to $\mathbf{6}$ produces $\mathbf{3 a}$ and a thiyl radical $\left(\mathrm{C}_{6} \mathrm{~F}_{5} \mathrm{~S}^{*}\right) .^{5}$ The $[\mathrm{Ir}(\mathrm{IV})]^{+}$species and $\mathrm{C}_{6} \mathrm{~F}_{5} \mathrm{~S}^{\cdot}$ are reduced back to the $[\operatorname{Ir}(\mathrm{III})]$ species and $\mathrm{C}_{6} \mathrm{~F}_{5} \mathrm{SH}$, respectively, by the action of the ascorbate anion $[\mathrm{AscH}]^{-},{ }^{13,14}$ which ultimately becomes dehydroascorbic acid (DHA). ${ }^{15}$ The additive $\mathrm{KHSO}_{4}$ might act by suppressing undesirable formation of a thiolate anion $\left(\mathrm{C}_{6} \mathrm{~F}_{5} \mathrm{~S}^{-}\right)$from $\mathrm{C}_{6} \mathrm{~F}_{5} \mathrm{SH}$.

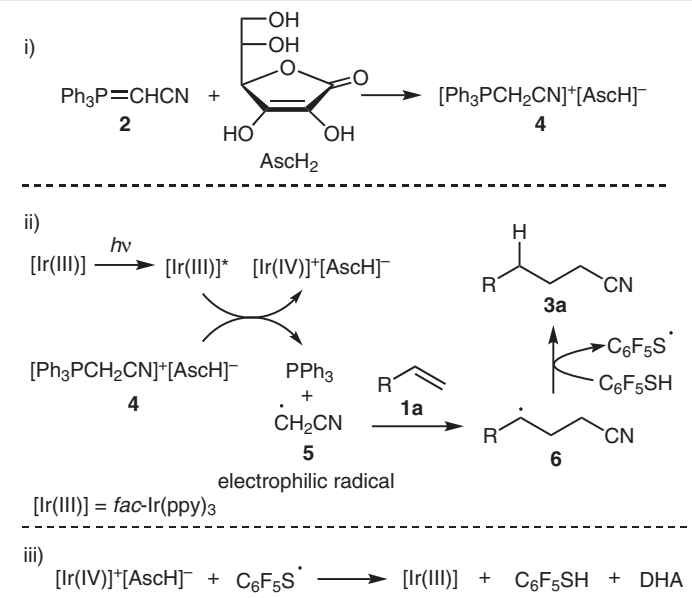

Scheme 2 Plausible mechanism for the formation of $\mathbf{3 a}$ from alkene $\mathbf{1 a}$ and phosphonium ylide $\mathbf{2}$

Various alkenes 1 were subjected to the 1,2-hydro(cyanomethylation) reaction with $\mathbf{2}$ (Table 1 ). A wide range of functional groups were tolerated to afford the corresponding elongated aliphatic nitriles $\mathbf{3 b} \mathbf{b}-\mathbf{g}$ in yields ranging from 74 to $88 \%$ (Table 1 , entries 1-6). Not only monosubstituted alkenes, but also polysubstituted alkenes, participated in the reaction. Geminally disubstituted alkenes $\mathbf{1 h}$ and $\mathbf{1 i}$ were suitable substrates (entries 7 and 8 ). Cyclic disubstituted alkenes $\mathbf{1 j}$ and $\mathbf{1 k}$ afforded the corresponding products $\mathbf{3} \mathbf{j}$ and $\mathbf{3 k}$ in yields of 59 and $79 \%$, respectively (entries 9 and 10). The reaction of the acyclic vicinally disubstituted alkenes $(Z)$ - and $(E)$-11 was sluggish, and the reason for the low yield of product $\mathbf{3 1}$ is unclear (entries 11 and 12). In the case of trisubstituted alkene $\mathbf{1} \mathbf{m}$, a mixture of diastereomers of $\mathbf{3 m}$ was formed through nonstereoselective transfer of a hydrogen atom to an intermediate tertiary radical species (entry 13). Even the tetrasubstituted alkene 1n underwent the reaction (entry 14 ). The 1,2-adduct 30 was obtained in 18\% NMR yield from styrene (10), and the final reaction mixture contained various products, probably as a result of the high reactivity of the benzylic radical intermediates (entry 15). ${ }^{16}$

Table 1 1,2-Hydro(cyanomethylation) of Various Alkenes 1 with Phosphorus Ylide $\mathbf{2}^{\mathrm{a}}$

Entry

a Reaction conditions: 1 (0.50 mmol), 2 (1.0 mmol), fac-Ir(ppy) 3 (1.0 mol\%), $\mathrm{C}_{6} \mathrm{~F}_{5} \mathrm{SH}(20 \mathrm{~mol} \%)$, ascorbic acid $(5.0 \mathrm{mmol}), \mathrm{KHSO}_{4}(1.5 \mathrm{mmol}), 1: 1$ $\mathrm{CH}_{3} \mathrm{CN} / \mathrm{H}_{2} \mathrm{O}(5.0 \mathrm{~mL})$, r.t., 40 h, blue LEDs $(470 \mathrm{~nm}, 23 \mathrm{~W})$.

b Isolated yield.

c NMR yield with 1,1,2,2-tetrachloroethane as internal standard. 
In the case of 1-benzofuran (7), the cyanomethyl radical species added regioselectively to form a benzylic radical species, giving the 2-substituted 2,3-dihydro-1-benzofuran 8 (Scheme 3).

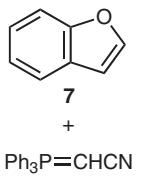

fac- $\operatorname{Ir}(\mathrm{ppy})_{3}(1.0 \mathrm{~mol} \%)$
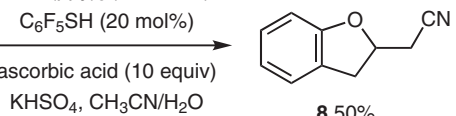

2 (2.0 equiv)

$\mathrm{KHSO}_{4}, \mathrm{CH}_{3} \mathrm{CN} / \mathrm{H}_{2} \mathrm{O}$

$850 \%$

Scheme 3 The addition reaction to 1-benzofuran (7)

Notably, even a branched $\alpha$-cyanoethyl group was attached to the $\mathrm{C}=\mathrm{C}$ double bond of 1a when $\alpha$-cyanoethylphophorus ylide $\mathbf{9}$ was employed (Scheme 4).

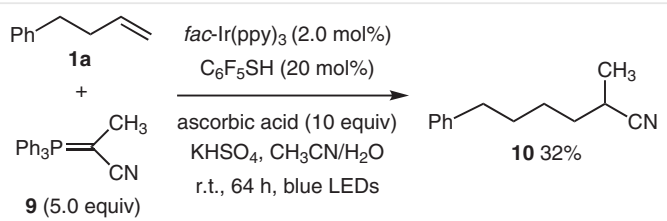

Scheme 4 The reaction with the $\alpha$-cyanoethylphosphonium ylide 9

A similar reaction to form elongated aliphatic nitriles from alkenes has been reported, ${ }^{8}$ in which a cyanomethyl radical species is generated from $\mathrm{CH}_{3} \mathrm{CN}$ by using an excess of dicumyl peroxide at a high temperature; these potentially hazardous conditions significantly limit the synthetic value of the method. The present reaction uses cyanomethylphosphonium ylide, which is stable and easily accessible, as the radical source, thereby providing a convenient method for synthesizing elongated aliphatic nitriles from alkenes. ${ }^{17}$

\section{Funding Information}

This work was supported by JSPS KAKENHI [Scientific Research (S) (15H05756) and (C) (16K05694)]

\section{Acknowledgment}

We thank Mr. H. Nikishima (Kyoto University) for his experimental contribution at a preliminary stage.

\section{Supporting Information}

Supporting information for this article is available online at https://doi.org/10.1055/s-0037-1612230.

\section{References and Notes}

(1) For reviews, see: (a) Narayanam, J. M. R.; Stephenson, C. R. J. Chem. Soc. Rev. 2011, 40, 102. (b) Skubi, K. L.; Blum, T. R.; Yoon, T. P. Chem. Rev. 2016, 116, 10035. (c) Romero, N. A.; Nicewicz, D. A. Chem. Rev. 2016, 116, 10075. (d) Twilton, J.; Le, C.; Zhang, P.; Shaw, M. H.; Evans, R. W.; MacMillan, D. W. C. Nat. Rev. Chem. 2017, 1, 0052. (e) Lee, K. N.; Ngai, M.-Y. Chem. Commun. 2017, 53, 13093. (f) Marzo, L.; Pagire, S. K.; Reiser, O.; König, B. Angew. Chem. Int. Ed. 2018, 57, 10034.

(2) For photoinduced reactions using phosphonium salts as the radical source, see: (a) Lin, Q.-Y.; Xu, X.-H.; Zhang, K.; Qing, F.-L. Angew. Chem. Int. Ed. 2016, 55, 1479. (b) Panferova, L. I.; Tsymbal, A. V.; Levin, V. V.; Struchkova, M. I.; Dilman, A. D. Org. Lett. 2016, 18, 996.

(3) For 1,2-bromo[(ethoxycarbonyl)methylation] of alkenes with $\mathrm{BrCH}(\mathrm{R}) \mathrm{CO}_{2} \mathrm{Et}$ as the radical source, see: (a) Nguyen, J. D.; Tucker, J. W.; Konieczynska, M. D.; Stephenson, C. R. J. J. Am. Chem. Soc. 2011, 133, 4160. (b) Arceo, E.; Montroni, E.; Melchiorre, P. Angew. Chem. Int. Ed. 2014, 53, 12064. (c) Cheng, J.; Cheng, Y.; Xie, J.; Zhu, C. Org. Lett. 2017, 19, 6452. (d) Magagnano, G.; Gualandi, A.; Marchini, M.; Mengozzi, L.; Ceroni, P.; Cozzi, P. G. Chem. Commun. 2017, 53, 1591. For a recent review, see: (e) Courant, T.; Masson, G. J. Org. Chem. 2016, 81, 6945.

(4) Miura, T.; Funakoshi, Y.; Nakahashi, J.; Moriyama, D.; Murakami, M. Angew. Chem. Int. Ed. 2018, 57, 15455.

(5) For the use of thiols as sources of electrophilic hydrogen atoms and the subsequent reactions between the resulting thiyl radicals and ascorbate anions, see: Guo, X.; Wenger, O. S. Angew. Chem. Int. Ed. 2018, 57, 2469.

(6) For a similar photoinduced elongation of alkenes using $\mathrm{BrCH}_{2}-$ $\mathrm{CO}_{2} \mathrm{Et}$ as the radical source, see: Sumino, S.; Fusano, A.; Ryu, I. Org. Lett. 2013, 15, 2826.

(7) For a review on 1,2-addition reactions with alkanenitriles as radical sources, see: Chu, X.-Q.; Ge, D.; Shen, Z.-L.; Loh, T.-P. ACS Catal. 2018, 8, 258.

(8) For 1,2-hydro(cyanomethylation) of alkenes by using $\mathrm{CH}_{3} \mathrm{CN}$ as the radical source, see: (a) Li, Z.; Xiao, Y.; Liu, Z.-Q. Chem. Commun. 2015, 51, 9969. See also: (b) Bruno, J. W.; Marks, T. J.; Lewis, F. D. J. Am. Chem. Soc. 1981, 103, 3608. (c) Sonawane, H. R.; Bellur, N. S.; Shah, V. G. J. Chem. Soc., Chem. Commun. 1990, 1603.

(9) For 1,2-difunctionalization of alkenes by using $\mathrm{CH}_{3} \mathrm{CN}$ as the radical source, see: (a) Bunescu, A.; Wang, Q.; Zhu, J. Angew. Chem. Int. Ed. 2015, 54, 3132. (b) Chatalova-Sazepin, C.; Wang, Q.; Sammis, G. M.; Zhu, J. Angew. Chem. Int. Ed. 2015, 54, 5443. (c) Lan, X.-W.; Wang, N.-X.; Bai, C.-B.; Lan, C.-L.; Zhang, T.; Chen, S.-L.; Xing, Y. Org. Lett. 2016, 18, 5986. (d) Wu, X.; Riedel, J.; Dong, V. M. Angew. Chem. Int. Ed. 2017, 56, 11589. (e) Liu, Y.-Y.; Yang, X.-H.; Song, R.-J.; Luo, S.; Li, J.-H. Nat. Commun. 2017, 8, 14720.

(10) For 1,2-bromo(cyanomethylation) of alkenes by using $\mathrm{BrCH}_{2} \mathrm{CN}$ as the radical source, see: (a) Voutyritsa, E.; Triandafillidi, I.; Kokotos, C. G. ChemCatChem 2018, 10, 2466. (b) Voutyritsa, E.; Nikitas, N. F.; Apostolopoulou, M. K.; Gerogiannopoulou, A. D. D.; Kokotos, C. G. Synthesis 2018, 50, 3395; See also refs. 3 (b) and $3(\mathrm{~d})$.

(11) Zhang, X.-M.; Bordwell, F. G. J. Am. Chem. Soc. 1994, 116, 968.

(12) Creutz, C. Inorg. Chem. 1981, 20, 4449.

(13) Warren, J. J.; Mayer, J. M. J. Am. Chem. Soc. 2010, 132, 7784. 
514

THEME

Synlett

T. Mira et al.

Letter

(14) For photocatalytic reactions using ascorbic acid as the reducant, see: (a) Mai, T.; Karmakar, A.; Reiser, O.J. Org. Chem. 2011, 76, 736. (b) Wallentin, C.-J.; Nguyen, J. D.; Finkbeiner, P.; Stephenson, C. R. J. J. Am. Chem. Soc. 2012, 134, 8875. (c) Supranovich, V. I.; Levin, V. V.; Struchkova, M. I.; Dilman, A. D. Org. Lett. 2018, 20, 840; See also ref. 5.

(15) Gerber, R. C. J. Chem. Educ. 2008, 85, 1237.

(16) The reactions of terminal alkyne such as 4-phenylbut-1-yne gave complex mixtures of products, in which the corresponding 1,2-hydro(cyanomethylation) product (a $\beta, \gamma$-unsaturated nitrile) was present in $\sim 10 \%$ yield as a $1: 1$ mixture of $E$ - and $Z$ isomers.

(17) 6-Phenylhexanenitrile (Ba); Typical Procedure

A vial (2-5 mL; Biotage, Fisher Scientific) equipped with a stirrer bar was charged with the phosphorus glide 2 (302 mg, $1.00 \mathrm{mmol})$, fac- $\operatorname{Ir}(\mathrm{ppy})_{3}(3.30 \mathrm{mg}, 0.005 \mathrm{mmol}, 1.0 \mathrm{~mol} \%)$, ascorbic acid ( $882 \mathrm{mg}, 5.00 \mathrm{mmol}$ ), and $\mathrm{KHSO}_{4}(207 \mathrm{mg}, 1.52$ $\mathrm{mmol}$ ). The vial was then flushed with argon gas and quickly capped with a Teflon septum. 4-Phenylbut-1-ene (ia, $67.6 \mathrm{mg}$, $0.51 \mathrm{mmol}), \mathrm{C}_{6} \mathrm{~F}_{5} \mathrm{SH}(20.0 \mathrm{mg}, 0.100 \mathrm{mmol}, 20 \mathrm{~mol} \%)$, distilled $\mathrm{CH}_{3} \mathrm{CN}(2.5 \mathrm{~mL})$, and $\mathrm{H}_{2} \mathrm{O}(2.5 \mathrm{~mL}$; degassed with argon gas for $30 \mathrm{~min}$ ) were added from a syringe, and the mixture was stirred vigorously for $40 \mathrm{~h}$ under blue LED lights ( $470 \mathrm{~nm}, 23 \mathrm{~W}$ ) while the vial was cooled with a fan. The mixture was then diluted with brine $(25 \mathrm{~mL})$ and extracted with $\mathrm{CH}_{2} \mathrm{Cl}_{2}(3 \times 25 \mathrm{~mL})$. The organic phase was dried $\left(\mathrm{Na}_{2} \mathrm{SO}_{4}\right)$, filtered, and concentrated under reduced pressure to give a residue that was purified by column chromatography [silica gel, hexane/EtOAc (9:1)] to give a colorless oil; yield: $70.7 \mathrm{mg}$ ( $0.41 \mathrm{mmol}, 80 \%)$.

IR (ATR): 2936, 2245, $1454 \mathrm{~cm}^{-1} \cdot{ }^{1} \mathrm{H}$ NMR (400 MHz, $\left.\mathrm{CDCl}_{3}\right)$ : $\delta=1.45-1.53(\mathrm{~m}, 2 \mathrm{H}), 1.63-1.73(\mathrm{~m}, 4 \mathrm{H}), 2.33(\mathrm{t}, J=7.2 \mathrm{~Hz}, 2$ $\mathrm{H}), 2.63(\mathrm{t}, J=7.6 \mathrm{~Hz}, 2 \mathrm{H}), 7.16-7.21(\mathrm{~m}, 3 \mathrm{H}), 7.26-7.31(\mathrm{~m}, 2$ H). ${ }^{13} \mathrm{C}$ NMR $\left(100 \mathrm{MHz}, \mathrm{CDCl}_{3}\right): \delta=17.1,25.3,28.3,30.5,35.5$, 119.7, 125.8, 128.3, 141.9. HRMS $\left(\mathrm{EI}^{+}\right): \mathrm{m} / \mathrm{z}[\mathrm{M}]^{+}$calcd for $\mathrm{C}_{12} \mathrm{H}_{15} \mathrm{~N}$ : 173.1204 ; found: 173.1205 .

Georg Theme Verlag Stuttgart · New York - Synlett 2019, 30, 511-514 